\title{
A more tubulocentric view of diabetic kidney disease
}

\author{
Letizia Zeni ${ }^{1,2,3}$ - Anthony G. W. Norden ${ }^{2}$ Giovanni Cancarini ${ }^{1,3}$. \\ Robert J. Unwin ${ }^{2,4}$
}

Received: 12 June 2017 / Accepted: 22 July 2017 / Published online: 24 August 2017

(C) The Author(s) 2017. This article is an open access publication

\begin{abstract}
Diabetic nephropathy (DN) is a common complication of Diabetes Mellitus (DM) Types 1 and 2, and prevention of end stage renal disease (ESRD) remains a major challenge. Despite its high prevalence, the pathogenesis of DN is still controversial. Initial glomerular disease manifested by hyperfiltration and loss of glomerular size and charge permselectivity may initiate a cascade of injuries, including tubulo-interstitial disease. Clinically, 'microalbuminuria' is still accepted as an early biomarker of glomerular damage, despite mounting evidence that its predictive value for DN is questionable, and findings that suggest the proximal tubule is an important link in the development of DN. The concept of 'diabetic tubulopathy' has emerged from recent studies, and its causative role in DN is supported by clinical and experimental evidence, as well as plausible pathogenetic mechanisms. This review explores the 'tubulocentric' view of DN. The recent finding that inhibition of proximal tubule (PT) glucose transport (via SGLT2) is nephro-protective in diabetic patients is discussed in relation to the tubule's potential role in DN. Studies with a tubulocentric view of DN have stimulated alternative clinical approaches to the early detection of diabetic kidney disease. There are tubular biomarkers
\end{abstract}

Letizia Zeni

1.zeni@ucl.ac.uk

1 Department of Medical and Surgical Specialities, Radiological Sciences and Public Health, University of Brescia, Piazza del Mercato 15, 25121 Brescia, Italy

2 UCL Centre for Nephrology, UCL Medical School, Royal Free Campus, Rowland Hill Street, London NW3 2PF, UK

3 Operative Unit of Nephrology, ASST Spedali Civili, Piazzale Spedali Civili 1, Brescia, Italy

4 Cardiovascular and Metabolic Diseases iMED ECD, AstraZeneca Gothenburg, Mölndal, Sweden considered as direct indicators of injury of the proximal tubule (PT), such as N-acetyl- $\beta$-D-glucosaminidase, Neutrophil Gelatinase-Associated Lipocalin and Kidney Injury Molecule-1, and other functional PT biomarkers, such as Urine free Retinol-Binding Protein 4 and Cystatin C, which reflect impaired reabsorption of filtered proteins. The clinical application of these measurements to diabetic patients will be reviewed in the context of the need for better biomarkers for early $\mathrm{DN}$.

Keywords Diabetic kidney disease - Microalbuminuria Hyperfiltration · SGLT2 nephro-protection · Diabetic tubulopathy $\cdot$ Tubular biomakers

$\begin{array}{ll}\text { Abbreviations } & \\ \text { ATP } & \text { Adenosine triphosphate } \\ \text { AGEs } & \begin{array}{l}\text { Advanced glycosylation end } \\ \text { products } \\ \text { Albumin:creatinine ratio }\end{array} \\ \text { ACR } & \text { Albumin-fluorescein isothiocy- } \\ \text { FITC-albumin } & \text { anate conjugate } \\ & \text { Alkaline phosphatase } \\ \text { ALP } & \text { Angiotensin II receptor type 1 } \\ \text { AT1 } & \text { Brush Border } \\ \text { BB } & \text { Chemokine (C-C motif) ligand 2 } \\ \text { CCL-2 } & \text { Connective tissue growth factor } \\ \text { CTGF } & \text { Diabetes mellitus } \\ \text { DM } & \text { Diabetic kidney disease } \\ \text { DKD } & \text { Diabetic nephropathy } \\ \text { DN } & \text { End stage renal disease } \\ \text { ESRD } & \text { Focal segmental } \\ \text { FSGS } & \text { glomerulosclerosis } \\ \text { FTB } & \text { Functional tubular biomarkers } \\ \text { Gpnmb } & \text { Glycoprotein non-metastatic mela- } \\ & \text { noma B }\end{array}$




GGT
GBM
GFR
GSC
GAG
GLT
H-FABP
HIF
ICAM-1
IL-1 $\beta$
IL-6
IL-8
IFTA

KIM-1

KLF6

L-PGDS

L-FABP

MIP-3 $\alpha$

miRNA

MAPK

MW

MCP-1

LMWP

NAG

NGAL

NO

NF- $\mathrm{KB}$

8-oHdG

8-oxodG

$\mathrm{P} 2 \mathrm{X} 4$ purinoreceptor

PKC

PT

PTECs

PAN

ROS

RANTES

RRT

RAS

RBP4

SGK-1

STAT-1
$\gamma$-Glutamyltransferase

Glomerular basement membrane

Glomerular filtration rate

Glomerular sieving coefficient

Glycosaminoglycan

Glucose transporter

Heart fatty acid binding protein

Hypoxia-inducible factors

Intercellular adhesion molecule 1

Interleukin $1 \beta$

Interleukin 6

Interleukin 8

Interstitial fibrosis and tubular

atrophy

Kidney injury molecule-1

Krueppel-like factor 6

Lipocalin-type prostaglandin-D

synthase

Liver-type fatty acid binding

protein

Macrophage inflammatory

protein-3

MicroRNA

Mitogen-activated protein kinase

Molecular weight

Monocyte chemoattractant

protein-1

Proteins of low molecular weight

$\mathrm{N}$-acetyl- $\beta$-D glucosaminidase

Neutrophil gelatinase-associated

lipocalin

Nitric oxide

Nuclear factor kappa-light-chainenhancer of activated $B$ cells

8-Oxo-7,8-dihydro-2-deoxyguanosine

8-oxo-7,8-dihydro-2'-

deoxyguanosine

P2X4R

Protein kinase $\mathrm{C}$

Proximal Tubule

Proximal Tubule Epithelial Cells

Purine Amino Nucleoside

Reactive Oxygen Species

Regulated on activation normal $\mathrm{T}$

cell expressed and secreted

Renal replacement therapy

Renin-angiotensin system

Retinol-binding protein 4

Serum and glucocorticoid-regu-

lated kinase 1

Signal transducer and activator of transcription 1
SGLT

NHE

STZ

STB

TLR

TGF- $\beta$

TBM

TGF

TNF- $\alpha$

UACR

VEGF

WT1

\section{Introduction}

Diabetic Nephropathy (DN) is one of the principal longterm microvascular complications of Diabetes Mellitus (DM) Types 1 and 2. It remains a leading cause of End Stage Renal Disease (ESRD) in the United States [1] and elsewhere requiring renal replacement therapy (RRT). The rising incidence and prevalence of DM worldwide [2] creates a pressing need for earlier diagnosis and effective treatment of DM and its complications, including DN.

Initially, DN is considered to be a progressive disease characterized by significant urinary protein excretion and hyperfiltration, leading eventually to renal failure. The classical model of DN divides it into two phases, incipient and overt, which includes five progressive stages: (1) normoalbuminuria ( $<30 \mathrm{mg} / \mathrm{g}$ creatinine); (2) microalbuminuria (30-299 mg/g); (3) macroalbuminuria ( $>300 \mathrm{mg} / \mathrm{g}$ ) or proteinuria $(>0.5 \mathrm{~g} / \mathrm{g})$; (4) estimated glomerular filtration rate (eGFR) $<30 \mathrm{ml} / \mathrm{min}$, irrespective of albuminuria or proteinuria status; and (5) the need for renal replacement [3]. The main features of the earliest and evident stage 2 are microalbuminuria and an increase in GFR, both considered markers of glomerular damage. However, in several studies of Type 1 and Type 2 DM patients, many exceptions to this have been found. Microalbuminuria can regress (to stage 1) or remain unchanged, and a substantial proportion of diabetic individuals with decreased GFR levels are normoalbuminuric [4, 5].

There is now growing evidence that the traditional picture of DN, which is that ESRD is preceded by increasing albuminuria and proteinuria, does not always apply. Recent clinical studies have demonstrated that the "non-albuminuric phenotype' is now becoming the predominant mode of DN presentation [6, 7]. While renin-angiotensin system (RAS) inhibitors have been shown to have an important action in reducing urinary albumin excretion, a positive response is not universal, and their effect may still depend more on small decreases in blood pressure and GFR. Therefore, perhaps there is another facet of nephron function, together with 
glomerular hemodynamics and the filtration barrier, that has a part to play in the pathophysiology of DN?

Indeed, recent findings have changed our overall concept of DN, reflected in the newer term of 'Diabetic Kidney Disease' (DKD) [8]. As a result of emerging evidence supporting a role for tubular involvement in DKD, interest has shifted to the proximal tubule (PT), which may play a role as an initiator, driver or contributor in the early pathogenesis of diabetes affecting the kidney.

We have conducted a literature review, firstly to address the questions of how the proximal tubule might interact with the glomerulus in early stages of DKD, and secondly to explore the evidence supporting a tubular role in initiating and/or amplifying renal damage due to DM, and lastly to determine which tubular biomarkers can potentially be used for the clinical care and follow-up of patients with diabetes. This review is not an argument against a central role for the glomerular filtration barrier or the strong evidence supporting early glomerular damage, but rather it is intended to highlight theories and evidence for PT involvement in DKD.

Although the term 'microalbuminuria' is widely used throughout the text, we recognize that it is potentially misleading. In fact, there is a continuum in the relationship between albuminuria and the risk of renal and cardiovascular disease, and the concept of a threshold level to define normality should be viewed with some caution [9].

\section{Microalbuminuria and hyperfiltration: an early tubular contribution to their development and a two-way interaction between glomerulus and tubule?}

Microalbuminuria, a well-known marker of loss of size and charge permselectivity at the glomerulus [10], together with glomerular hyperfiltration, defined as a supraphysiologic increase in whole kidney GFR [11], highlight structural and functional changes of the glomerulus in early DKD. While it is often difficult to know what constitutes relative hyperfiltration in many Type 2 diabetics with a long history of DM and who come late to the attention of a nephrologist, there is a close interrelationship between the tubule and these classical early biomarkers of DKD.

Conventionally, the underlying mechanism of microalbuminuria in early stages of DN has been ascribed to increased glomerular filtration due to hyperfiltration or glomerular barrier damage, or some combination of the two. However, putative early involvement of the tubule, in addition to glomerular leakage, in generating microalbuminuria was highlighted in the late 1980s by clinical observations in patients with early onset Type $1 \mathrm{DM}$ of relatively short duration [12]. A good correlation was found between urinary albumin excretion and markers of tubular dysfunction. Based on this finding, many animal models have been created to try to clarify the underlying mechanism. Using renal micropuncture and evaluation of endocytosis by Fluorescein-IsoThiocyanate-(FITC)-labelled albumin, and immunoelectron microscopy, a Japanese group showed in 2001 that streptozotocin (STZ)-induced diabetic rats had reduced reabsorption of albumin in proximal tubules (PT) compared with control rats. This could be partly explained by decreased albumin endocytosis with reduced megalin expression. Of importance in this study is that no increase in GFR was evident in the diabetic rats [13]. Subsequently, other groups found no significant difference in Glomerular Sieving Coefficient (GSC) between control and insulin-dependent diabetic rats, despite the presence of albuminuria in the diabetic animals. The excess urinary albumin excretion was ascribed to changes in PT albumin handling, highlighting the importance of the PT in generating albuminuria [14].

Interestingly, it has been argued that the role of the PT in determining albuminuria in renal disorders has reduced the importance of defects in the glomerular barrier. According to this 'retrieval hypotheisis', normal glomeruli filter high levels of albumin, which appears in the urine in nephrotic amounts only if tubular reabsorption does not occur. This means that albuminuria is primarily of tubular origin [10]. In 2007, a study performed by Russo et al. provided new insights into the contribution of post-glomerular reabsorption in excretion of urinary albumin. In their work, they reported firstly a very much higher GSC of albumin (0.034) in non-proteinuric rats than previously, and secondly they claimed that a large amount of filtered albumin underwent a rapid retrieval process via transcytosis by proximal tubule cells (PTCs); and lastly that in rats made nephrotic by purinomycin (the PAN rat model), the rate of uptake of albumin by the PT was decreased [15]. Although changes in the albumin GSC in PAN rats cannot be excluded, previous studies have demonstrated that for molecules of the same size as albumin, glomerular permeability is not altered in PAN [15, 16]. Their estimated value for GSC in rats is much higher than other measurements reported in rats. Also, a study in humans reported a much lower estimate in normal individuals, namely $8 \times 10^{-5}$ [17]. It has been suggested that complete retrieval of the proposed amount of filtered albumin in rats with such high GSC would be unachievable [18].

Nevertheless, impaired tubular uptake and increased glomerular leakage are not mutually exclusive events [19], and both are potentially responsible for microalbuminuria in early stage DKD. Even early glomerular disease and loss of size and charge permselectivity in DM with increased albumin leakage may not cause microalbuminuria, if normal proximal tubular function can remove the excess albumin from the glomerular filtrate. Although the reserve capacity for protein uptake by the PT in humans is unknown, it is likely that the tubule does have some spare capacity for 
reabsorption. This suggestion is supported by the following study in the rat. Wagner et al. demonstrated that the PT regulates albumin excretion rate. In their experiments, PTs responded to an acute exogenous overload of albumin by decreasing the amount of albumin retrieved; whereas after inducing increased endogenous albumin exposure from leaky glomeruli, PTs increased the proportion of albumin taken up. So, there is some evidence for potentially large reserve capacity of PTs to reabsorb filtered albumin [20]. Dissociation between increased glomerular leakage of albumin and microalbuminuria in diabetic patients has been suggested by several clinical studies [21, 22]. In a recent study of patients with Type $2 \mathrm{DM}$, an association between PT dysfunction and podocyte biomarkers was found, which was independent of the level of albuminuria and of renal function [22].

Dickson et al. critically re-examined the steps leading to uptake and metabolism of filtered albumin in the PT and determined which stages were interrupted [19]. They highlighted the complexity of protein handling throughout the nephron. A brief summary of the studies reporting evidence of proteinuria due to tubular damage in the course of DM is presented in Table 1.

Recent findings from animal models have provided evidence for a minor contribution from other parts of the nephron to protein reabsorption, in addition to the major role of megalin-cubilin-mediated endocytosis in the PT [27]. The amount and clinical importance of these other pathways remain to be determined, particularly when glomerular ultrastructural damage and impaired PT protein uptake occur.

Regardeless of the individual contribution of either the glomerulus or PT to the quantity of urinary albumin excretion in DKD, it has been proposed that increased protein leakage from the glomerulus has intrinsic renal (tubular) toxicity [28] that may provide a pathogenic link between glomerular damage and tubulo-interstitial injury in proteinuric renal diseases. Protein overload due to impaired glomerular permeability causes excessive tubular protein reabsorption and abnormal protein accumulation in endolysosomes, which may, theoretically, up-regulate many NF-кB (nuclear factor kappa-light-chain-enhancer of activated B cells)dependent or -independent inflammatory genes (chemokines, cytokines and endothelin) in the PT epithelium. These are potentially capable of triggering an interstitial inflammatory reaction. Consequently, the proximal tubule has a profibrotic and proinflammatory role leading to synthesis and deposition of extracellular matrix, and contributing to renal scarring [28]. Interestingly, Nielsen et al. have showed that in an FSGS (Focal Segmental GlomeruloSclerosis) mouse model, there is a counteracting mechanism against protein overload by the PT. Inflammatory mediators originating from PTECs during protein overload occurred early in the course of exposure. However, the lysosomal system showed a well-adapted response to protein load by increasing synthesis of factors for lysosomal proteolysis. Are there any other injury sensors that might stimulate inflammation and fibrosis in the PT in response to protein overload [29]? Although the importance of proteinuria as a marker and driver of kidney disease has been examined in many proteinuric renal disorders, a study by Guo et al. showed, interestingly, that tubular injury is dependent only on the degree of podocyte damage and not on albuminuria per se $[29,30]$.

\section{Hyperfiltration: more than a vascular effect?}

Despite difficulties in a precise definition or threshold, increased GFR as a marker of glomerular hyperfiltration occurs early in the clinical course of DKD and is considered to be an important factor in the initiation and progression of kidney damage. It is thought to be due to a rise in intraglomerular pressure (causing barotrauma) and renal blood flow, resulting from an imbalance of vasoactive humoral factors that control pre-and post-glomerular arteriolar tone [11].

Clearly, a rise in hydrostatic pressure in the glomerulus may result in higher filtration pressure with an increase in the amount of protein passing through the glomerular barrier [11]. Therefore, the amount of protein delivered to the PT per unit time for potential reabsorption increases with hyperfiltration.

As discussed in a recently published review, the pathogenesis of glomerular hyperfiltration is complex and includes overlapping mechanisms, as summarized in the 'Tubular Theory'. This theory proposes that several tubular changes inhibit tubuloglomerular feedback (TGF). This negative feedback mechanism is normally controlled by sodium and chloride delivery to the macula densa of the loop of Henle. In diabetes with hyperglycemia, increased filtered glucose stimulates PT glucose reabsorption that is coupled to sodium, thereby reducing its delivery to the macula densa, and decreasing TGF feedback. This results in afferent arteriolar vasorelaxation, increased renal blood flow and hyperfiltration [31]. Interestingly, a study exploring the effect of glomerular hyperfiltration on tubular dysfunction reported that two markers of tubular damage (Neutrophil gelatinase-associated lipocalin NGAL and Kidney Injury Molecule-1 KIM-1) showed increased excretion in the urine of those with glomerular hyperfiltration and it correlated positively with GFR. These findings suggest that glomerular hyperfiltration is related to altered tubular function in DM patients [32].

Crucially, a study by Vallon et al. showed that inhibition of PT glucose reabsorption increased the amount of sodium delivered to the macula densa, stimulating TGF and reducing glomerular hyperfiltration, without a change in blood glucose concentration. The tubular hypothesis of diabetic 


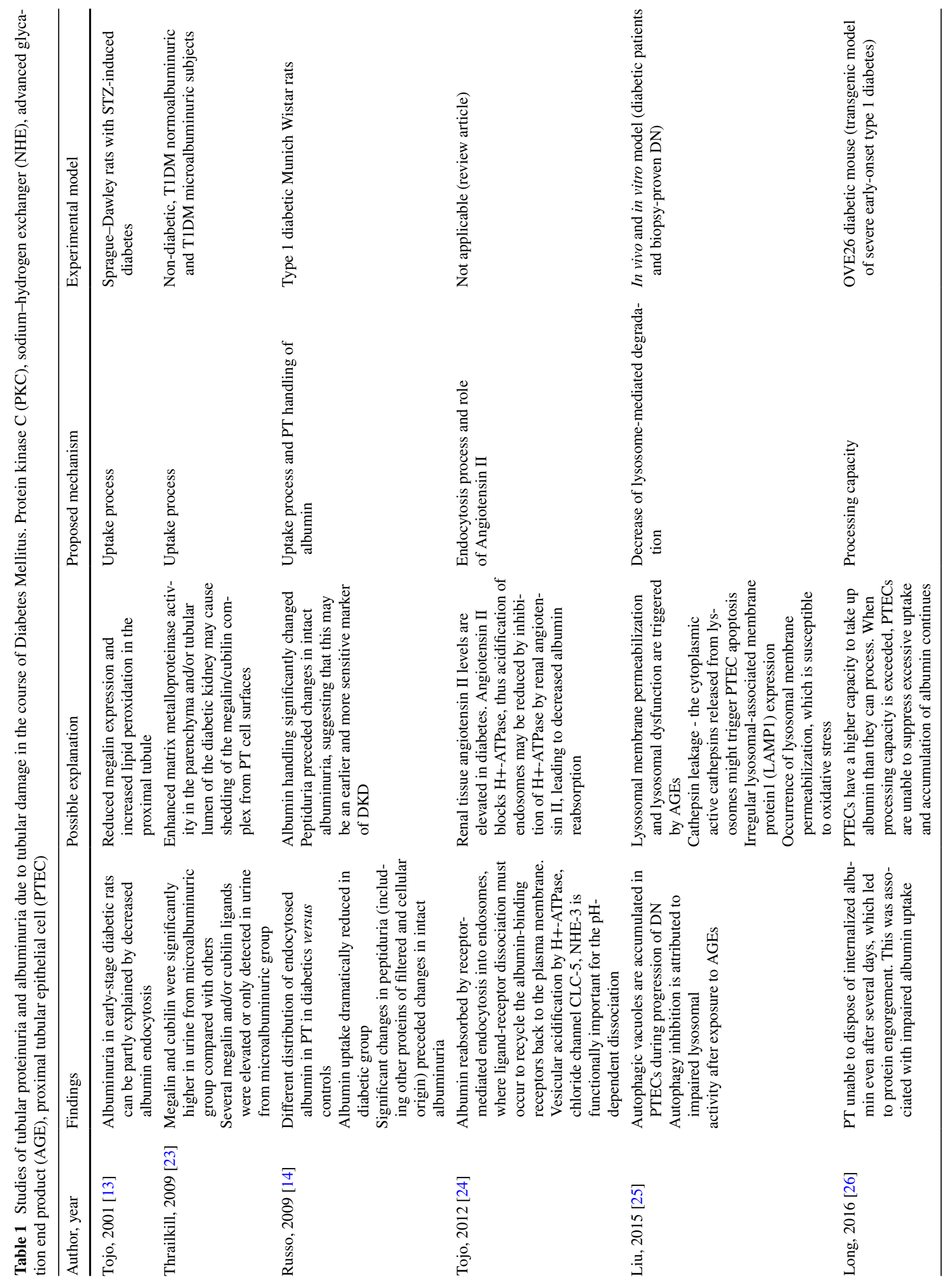


glomerular hyperfiltration suggests that the PT has a role in determining hyperfiltration, in addition to blood glucose control, through glucose reabsorption [33].

As well as increased glucose overload in the course of DM, parallel tubular hypertrophy and upregulation of sodium-glucose cotransporter 2 (SGLT2) and sodium-hydrogen exchange (NHE) 3 may also contribute to increasing hyperfiltration. Furthermore, enhanced PT reabsorption may reduce intratubular pressure and so increase the net pressure gradient for filtration across the glomerulus [11].

Understanding the relationship between damage to different structures in the nephron and determining which lesions are primary is a major challenge (Fig. 1). However, there appears to be good evidence for early tubular involvement in the course of DKD and its role in the pathogenesis of both microalbuminuria and hyperfiltration.

\section{The proximal tubule: a therapeutic target for nephro-protection}

In normoglycemic humans, the high-capacity cotransporter SGLT2 is responsible for some $97 \%$ of glucose reabsorption by the PT, and retrieves filtered glucose with sodium in a 1:1 molar ratio; SGLT1 in the later part of the PT reabsorbs any remaining luminal glucose. The two basolateral glucose transporters, GLUT1 and GLUT2 can return reabsorbed glucose to the bloodstream. Different structures within the PT co-operate to help to maintain the blood glucose level [34].

The glucose load in PT is increased with hyperglycemia in diabetes and exceeds the renal transport maximum for glucose, leading to glycosuria in poorly controlled DM. Blocking glucose reabsorption in the PT increases glucose excretion in the urine and can reduce high circulating blood glucose levels. Canagliflozin is an example of a SGLT2 inhibitor that was approved by the Food and Drug Administration (FDA) in 2013 as a new glucose-lowering medication for adults with type 2 diabetes.

Use of SGLT2 inhibitors has brought new insights into the complex mechanism of PT glucose reabsorption. Previously, only medication blocking RAS showed some nephroprotective effects in patients with DM. New therapeutic strategies to improve renal outcome have been sought and in a recently published study Empagliflozin, another selective SGLT2 inhibitor, significantly (and unexpectedly) slowed progression of DKD and lowered the risk of clinically relevant renal events in type 2 DM patients [35], as well as heart failure. This new class of drug appears very promising. In addition to the EMPA-REG study, there are several ongoing studies looking at the effects of SGLT2 inhibition on cardiovascular and kidney outcomes, including DECLARE, CANVAS, and CREDENCE [36].
Why does targeting the SGLT2 cotransporter improve renal outcomes in addition to many metabolic and cardiovascular complications in DM? Current thinking is that the beneficial effect of SGLT2 inhibition is primarily a direct nephro-vascular effect [31]. Activation of TGF is a myogenic response to distal sodium delivery, inducing glomerular arteriolar vasoconstriction and reduction in GFR [31]. DM with hyperglycemia is associated with renal sodium retention and increased proximal tubular reabsorption, reducing distal delivery and decreasing TGF, and thus hyperfiltration [34]. Therefore, the beneficial renal effect of Empaglifozin highlighted in the EMPA-REG OUTCOME Trial is thought to be the consequence of reducing intraglomerular pressure and barotrauma to podocytes [31]. This mechanism may also underlie the associated decrease in urinary albumin excretion seen with SGLT2 inhibition [37].

Despite the reduction in glomerular hyperfiltration and podocyte stress, SGLT2 inhibitors have other potentially nephro-protective mechanisms that may be renal or systemic. Looking at the former, some important pathophysiological changes in the nephron have been reported in relation to DM [34]:

Upregulation in renal SGLT2 expression has been demonstrated in both human cells and some animal models of Type 1 and Type 2 DM [34]. It is still unclear whether this phenomenon is the result of hypertrophy of PT in $\mathrm{DM}$ and/or of an 'energy/glucose saving' response to a glucose sensor downstream of the early proximal tubule. This maladaptive process of SGLT2 upregulation helps to sustain high blood glucose. Therefore, targeting this upregulated cotransport specifically, means a better glycosuric and blood glucose-lowering effect and, perhaps, also a prevention of glucose toxicity to PTEC [33]. Upregulation of SGLT2 has been demonstrated in both human and animal models of type 1 and type $2 \mathrm{DM}$, but what happens to SGLT1 activity is more controversial. Under high glucose conditions, SGLT1 expression has been reported to be increased, reduced or unchanged. In STZ-diabetic rats and in diabetic obese Zucker rats an increase in SGLT1 mRNA expression was documented, whereas in Akita mice models of type $1 \mathrm{DM}$, as well as in normoglycemic rats under pharmacological or genetic SGLT2 inhibition, SGLT1 renal protein expression decreased. Thus, these animal studies show contrasting changes in SGLT1 levels in different rodent models of diabetes [38]. When SGLT2 function is saturated by glucose overload due to DM or, alternatively, is inhibited pharmacologically or genetically, does SGLT1 increase its activity to prevent a loss of glucose in the urine? Rieg et al. showed that with genetic or pharmacological inhibition of SGLT2 in non-diabetic mice, a compensatory increase in SGLT1-mediated transport 


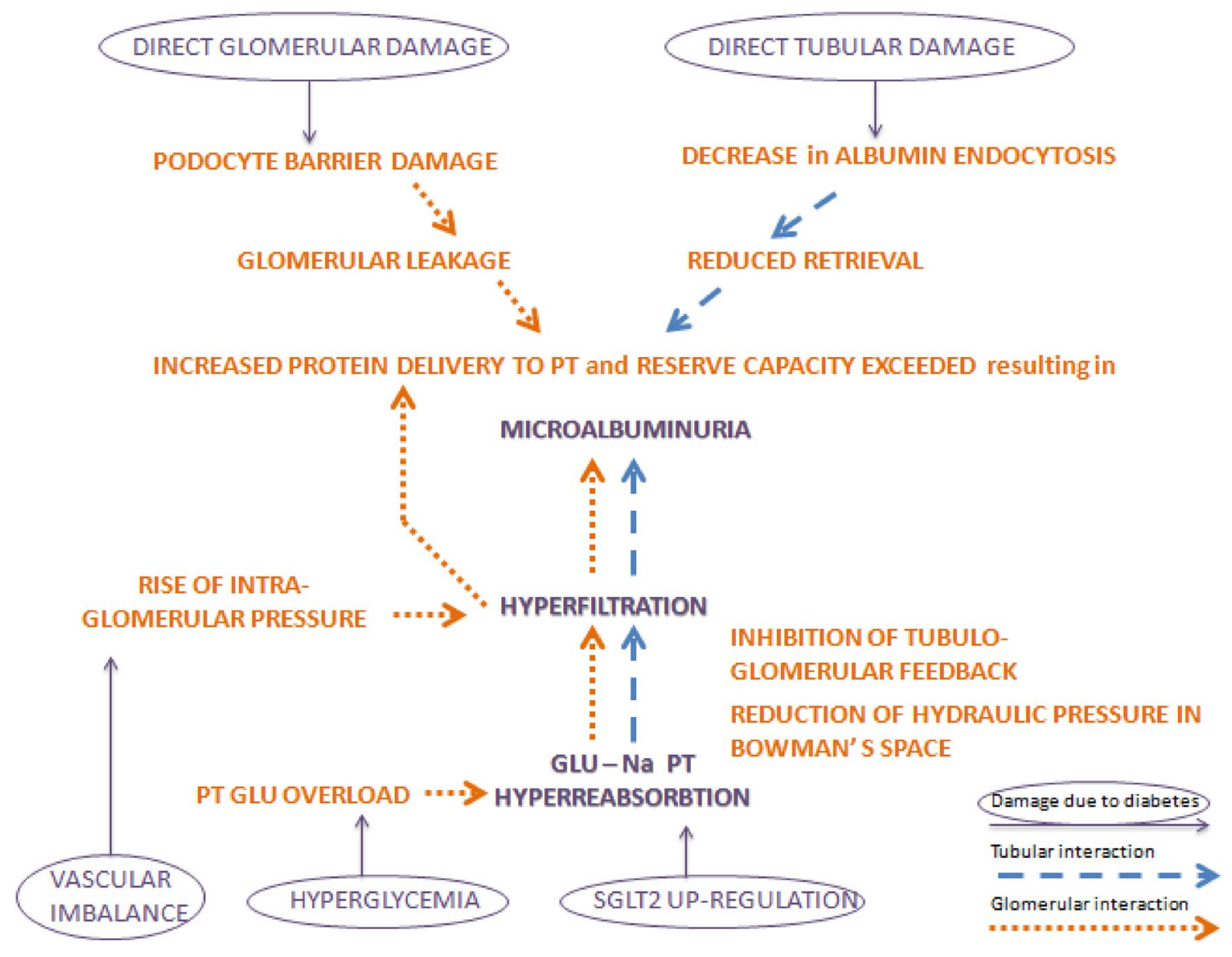

Fig. 1 Interactions between glomerulus and proximal tubule (PT) in the pathophysiology of microalbuminuria, hyperfiltration and proximal tubule glucose (GLU) reabsorption in the context of DKD

occurs, which explains why renal fractional glucose reabsorption is maintained at $40-50 \%$ [39]. Following this reasoning, Abdul-Ghani et al. [40] in 2013 suggested that SGLT2 inhibitors cause SGLT1 to reabsorb glucose at its maximum capacity, unmasking its global reabsorption reserve, in accordance with the results of Powell et al. [41]. The latter group demonstrated that in SGLT2 knockout mice urine glucose excretion is approximately $30 \%$ of filtered glucose. Consistent with this, observations in humans showed a fractional glucose reabsorption rate of about $40-50 \%$ following a maximal effective dose of SGLT2 inhibitor. A compensatory effect of SGLT1 is also supported by micropuncture studies along the late proximal tubule in Sglt2-/- mice [38]. Thus, there is an increase in glucose reabsorption mediated by SGLT1 when the principal cotransporter (SGLT2) is functionally deleted. Therefore, when a compensatory increased activity of SGLT1 occurs in response to an excessive glucose to be reabsorbed, one would expect an upregulation of this tubular transporter. However, in a genetic model of T1DM (Akita mice) and in response to SGLT2 gene knockout and pharmacological inhibition of SGLT2 in non-diabetic mice, SGLT1 protein expression was found to be reduced. How can this apparent discrepancy be explained? Downregulation of SGLT1 expression, would attenuate any increase in glucose reabsorption and promote glycosuria, which has been put forward as protective mechanism for the kidney. The late PT is highly vulnerable to hypoxia and acute injury in general, and Vallon et al. proposed that downregulation of SGLT1 expression could mitigate or prevent glucose toxicity in this nephron segment [42].

Rat studies suggested the translocation of GLUT2 from basolateral to apical brush border PT membrane in diabetes [43]. A similar mechanism occurs in the small intestine, where SGLT1 sensitivity is required for GLUT2 translocation. Does SGLT2 in the kidney play the same role of sensor that SGLT1 has in the small intestine to allow GLUT2 translocation? Furthermore, does the translocation occur even if SGLT2 is pharmacologically inhibited? Moreover, it is still unknown whether the translocation of GLUT2 occurs in humans 
and if a GLUT2 contribution in facilitating glucose reabsorption when PT lumen is exposed to high glucose concentration is physiologically relevant [34].

Recent evidence suggests a functional link between SGLT2 and the sodium-hydrogen exchanger (NHE) 3 in that SGLT2 inhibition may also inhibit NHE3 in the proximal tubule. Taking all the evidence together, it is suggested that the nephro-protective effects of SGLT2 inhibitors are directly or indirectly related to decreased sodium reabsorption. However, an alternative explanation has been proposed [44]. Firstly, Wakisaka suggested that SGLT2 inhibitors may increase sodium reabsorption in the proximal tubule [45], in contrast to the still widely accepted explanation for SGLT2 inhibition and nephro-protection. However, the reasoning is that in the course of SGLT2 inhibition, SGLT1 has a greater role in glucose reabsorption with a glucose to sodium ratio of $1: 2$, rather than $1: 1$ with SGLT2. Secondly, Wakisaka proposed that SGLT2 inhibition and nephro-protection is not dependent entirely on TGF. In fact, in the 1990s the presence of SGLT2 and GLUT1 was also recognised in glomerular mesangial cells. Given that the loss of mesangial contractility is hypothesized to be another potential mechanism for glomerular hyperfiltration, Wakisaka explored the effect of high glucose concentration on mesangial cells. After incubation of rat mesangial cells for 6 days in $20 \mathrm{mM}$ glucose, the contraction of mesangial cells in response to angiotensin II showed a decrease. This mechanism was ascribed to SGLT2 acting as a glucose sensor and sodium-calcium exchanger, because Phlorizin, a competitive inhibitor of SGLT1 and SGLT2, attenuated mesangial cell dysfunction, normalizing its contractile response [46]. The author concluded that the nephro-protective effect of SGLT2 inhibition was partially driven by its direct cellular action on mesangial cells, offering a new perspective [45].

The kidney has a complex structure-function relationship and nephro-protection is likely to depend on several mechanisms yet to be elucidated. In this sense, many pleiotropic effects of SGLT2 inhibition have been postulated. Given that the PT is an actively transporting segment of the nephron, with a high number of transporters requiring a continuous energy supply, and with a large number of mitochondria in PTECs, we should consider the 'thrifty substrate hypothesis' in this context. According to this hypothesis, SGLT2 inhibition through mild ketosis promotes $\beta$-hydroxybutyrate uptake in the myocardium and kidney. This substrate selection improves mitochondrial efficiency and ATP generation. In addition, the modest hemoconcentration that follows SGLT2 inhibitor treatment may increase tissue oxygen delivery [47]. Another mechanism that also might contribute to nephro-protection of SGLT2 inhibitors is the increased renal content of HIF1- $\alpha$ [42].
Is the downregulation of SGLT1 expression a further nephro-protective mechanism? Could the sodium-glucose cotransporter SGLT1 be a second renal therapeutic target in DKD? Although this has been considered, its main target, and potential source of benefit, would be inhibiting intestinal absorption of glucose and postprandial excursions in blood glucose. How significant for nephro-protection is any effect on mesangial cells? Are there additional effects of SGLT2 inhibitors that explain the positive renal outcome in DM patients? Considering the evidence as a whole, renal glucose reabsorption is 'dysregulated' in DM and the data so far suggest that several mechanisms may underlie nephroprotection by SGLT2 inhibitors. More studies are needed to understand better how the PT handles glucose in DM.

\section{Diabetic tubulopathy: from pathophysiological mechanisms to histological data and evidence for a causative role for the renal tubule in DKD}

The interplay of the glomerulus and proximal tubule in DKD has been described in the pathogenesis of proteinuria, hyperfiltration and, importantly, nephro-protection. Nevertheless, there are findings that suggest a primary role for the PT in causing nephron injury and dysfunction, defined by the term 'Diabetic Tubulopathy' [48]. Because of their position and major reabsorptive role within the nephron, PTECs are exposed to factors in the glomerular filtrate, in the peritubular capillary blood supply, and in the interstitium. Consequently, they can be injured by a variety of potentially damaging agents that can trigger a pro-inflammatory and pro-fibrotic response causing tissue injury. In 1999, Gilbert and Cooper highlighted non-glomerular mechanisms involved in tubular cell damage in diabetes, emphasising that tubulo-interstitial injury was more than could be explained by glomerular injury alone [49].

The factors directly related to glucose metabolism, and potentially implicated in determining the pro-inflammatory and pro-fibrotic phenotype of the renal tubule in DKD, are a high glucose concentration and formation of advanced glycosylation end-products (AGEs). A summary of the main mechanisms thought to be involved is shown in Table 2 . Why are PTECs so vulnerable to glucose damage? PTECs are exposed to glucose apically from the filtered glucose load or basolaterally through elevated interstitial tissue concentrations of glucose. PTECs cannot decrease glucose transport to prevent excessive changes in intracellular glucose when exposed to high glucose concentrations [50].

However, there are other stimuli, not strictly related to glucose control that may affect the proximal tubule, for example, activation of local vasoactive hormone systems that cause hemodynamic changes. Over-expression of endothelin [49] and local angiotensin II in the renal tubule, 
activation of vascular endothelial growth factor (VEGF), and reduction of nitric oxide (NO) $[52,53]$ may cause vasoconstriction of the afferent and efferent arterioles, as well as the interlobular arteries. The combination of several vascular and metabolic effects may induce ischemic damage to PTECs. This may cause elevated energy demand of tubules due to increased reabsorption of glucose, AGEs and proteins, as well as reductions in peritubular blood flow with post-glomerular vasoconstriction and capillary loss following tubulo-interstitial expansion [49]. In addition, elevated blood pressure, often associated with impaired glucose control, may induce mechanical stress in the peritubular capillary network, which compared with the glomerulus is poorly adapted to cope with an increased blood pressure [49] and mechanical shear stress. All the changes in the vascular factors mentioned above can lower post-glomerular blood flow in diabetes and contribute to further reductions in oxygen delivery to the tubules and hypoxia.

As well as hemodynamic changes, other pathways are likely to contribute to the pathogenesis of tubular damage in DKD. Purinergic signalling may be involved, since it has been shown that this pathway is part of an inflammatory cascade and can lead to renal glomerular, tubular and vascular cell damage in a variety of inflammatory renal diseases, including DKD. Local productions of chemokines, adhesion molecules, and inflammatory cytokines are upregulated by chronic stimulation from hyperglycemia and other modulators [54]. In type 2 diabetic patients with nephropathy, tubular P2X4R (P2X4R purinoreceptor) expression is upregulated and closely related to NLRP3 inflammasome activation and renal interstitial inflammation [55].

Recent studies have also shown the importance of the endocannabinoid system in normal PTC function. In the model of Jenkin et al., increased circulating endocannabinoids in DM modify the expression of cannabinoid receptors in PTECs that might participate in activation of inflammation and cell hypertrophy, as well as in tubular cell dysfunction [56]. In DKD, the purinergic and endocannabinoid systems deserve further investigation as potential targets for therapeutic intervention. Finally, there are a number of pro-inflammatory factors abnormally filtered by altered glomeruli in the course of diabetes that could disrupt PTEC function, including IL-6, Il-8, IL-1 $\beta$, ROS, MCP-1 and RANTES [57].

Given the uncertainty and speculation over its pathogenesis, is diabetic tubulopathy a real entity in DKD and does it have any implications for treatment? A close correlation between the extent of tubulo-interstitial injury and long-term renal function in a variety of primary glomerular diseases has been demonstrated [49]. Furthermore, the extent of renal dysfunction is generally poorly associated with changes in glomerular morphology, whereas it correlates well with chronic tubulo-interstitial injury [48]. A recent review of the histological changes in early DKD described tubular cell hypertrophy, thickening of the tubular basement membrane, and interstitial inflammation with mononuclear cell infiltration. Progression of these early tubular abnormalities leads to interstitial fibrosis and tubular atrophy (IFTA) [58].

Brito et al. reported that in T1DM, the tubular cell basement membrane (TBM) width showed a strong correlation with glomerular basement membrane (GBM) width and mesangial expansion, the two most important and characteristic findings in the glomeruli of DKD. In the same report, TBM and GBM width were more closely correlated with glycosylated haemoglobin than other renal structural measures [59]. Moreover, the first measurable change, GBM thickening, has been detected very early in the course of DKD within 1.5 to 2.5 years after onset. Therefore, the parallel change in TBM may also occur very early and is a primary abnormality, and it is not secondary to glomerular hemodynamic changes [60].

Furthermore, early changes have been found in the PT in the rat model of Streptozotocin-induced diabetes: an early hyperplastic phase, followed by either transition to hypertrophy or cellular senescence. An accelerated senescent phenotype was also found in tubular cells of T2DM patients with nephropathy [61]. PTECs show increased lipofuscin pigment and vacuolarization, perhaps due to a high tubular lysosomal load and cell adaptation to stressful stimuli such as hyperglycemia, glycogen accumulation and subnuclear lipid vacuolarization [58].

In the later stages of DKD in both T1DM and T2DM patients, abnormalities involving the glomerulotubular junction have been described, with a glomerulus without a tubular attachment and known as an 'atubular glomerulus' (AG), which is non-functioning, or an atrophic tubule [60]. Najafian et al. showed that the fractional volume of atrophic tubules, percent of atubular glomeruli, and percent of glomeruli with tip lesions accounted for $94 \%$ of the GFR variability in diabetic patients, highlighting the importance of AG and glomerulotubular junction abnormalities in the development and progression of DN [62].

\section{Tubular biomarkers: use in clinical care}

The significant incidence and prevalence of DKD across diabetic populations and the limitations of microalbuminuria have emerged recently. Novel and better biomarkers for clinical diagnosis and management of DKD are needed to provide earlier diagnosis and more accurate prognosis. Microalbuminuria does still have a useful role in screening diabetic patients for DKD. It has several advantages: it is organ specific and a marker of generalized endothelial dysfunction with important prognostic implications for cardiovascular and renal outcomes [63], and measurements 
Table 2 Mechanisms of damage due to high glucose concentration and advanced glycosylation end-products (AGEs) on the renal tubule in diabetes mellitus

\begin{tabular}{|c|c|c|}
\hline Stimulus & Injury pathway & Effects on proximal tubule \\
\hline \multirow[t]{10}{*}{ High glucose } & Increased expression of the pro-fibrotic cytokine TGF- $\beta$ & $\begin{array}{l}\text { Production of collagens type I and type IV with autocrine } \\
\text { and paracrine effects on interstitial cells [49] }\end{array}$ \\
\hline & $\begin{array}{l}\text { Acceleration of polyol pathway metabolism and accumu- } \\
\text { lation of sorbitol }\end{array}$ & Stimulation of extracellular matrix expression [49] \\
\hline & $\begin{array}{l}\text { Increased glucose uptake induces angiotensin II, TGF- } \beta \\
\text { and cyclin-dependent kinase inhibitors }\end{array}$ & $\begin{array}{l}\text { Cell cycle arrest and a switch to tubular hypertrophy and a } \\
\text { senescence-like phenotype [51] }\end{array}$ \\
\hline & Promotion of angiotensinogen and AT1 expression & $\begin{array}{l}\text { Increased TGF } \beta 1 \text { expression and PTECs hypetrophy oxida- } \\
\text { tive stress [49] }\end{array}$ \\
\hline & $\begin{array}{l}\text { Production of VEGF, TGF } \beta \text {, IL-6, CCL-2 partly through } \\
\text { MAPK, PKC signalling, TLR }\end{array}$ & $\begin{array}{l}\text { Neo-angiogenic, pro-fibrotic and pro-inflammatory PTECs } \\
\text { shift [48] }\end{array}$ \\
\hline & Upregulation of MIP-3 $\alpha$ & Intracellular oxidative stress [48] \\
\hline & $\begin{array}{l}\text { KLF6 over-expression and activation of } \mathrm{p} 38 \text { signaling and } \\
\text { activator protein-1 }\end{array}$ & Promotion of epithelial mesenchymal transition [48] \\
\hline & Generation of intracellular (mitochondrial) ROS & $\begin{array}{l}\text { Reduction of NO and vasoconstriction of peritubular } \\
\text { vessels. Pro-inflammatory gene upregulation. Oxidative } \\
\text { stress [52] }\end{array}$ \\
\hline & SGK-1 overexpression & $\begin{array}{l}\text { Increased proximal tubular cell growth, progression through } \\
\text { the cell cycle, and inhibited apoptosis [50] }\end{array}$ \\
\hline & $\begin{array}{l}\text { Inhibition of hypoxia-induced activation of HIF and } \\
\text { VEGF expression }\end{array}$ & Reduced protection of hypoxic tissues [50] \\
\hline \multirow{4}{*}{$\begin{array}{l}\text { Advanced glycosyla- } \\
\text { tion end-products } \\
\text { (AGEs) }\end{array}$} & $\begin{array}{l}\text { Activation of intracellular second messenger mitogenic } \\
\text { activated protein kinase }\end{array}$ & Increased TGF $\beta 1$ expression [49] \\
\hline & $\begin{array}{l}\text { Increased in cytosolic phospholipase } \mathrm{A} 2 \alpha \text { activity and } \\
\text { cellular phosphoinositol } 4,5 \text { bisphosphate production }\end{array}$ & Generation of intracellular ROS and Oxidative stress [52] \\
\hline & 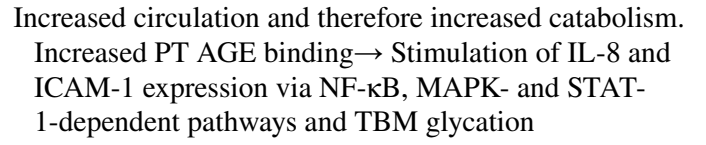 & Infiltration of Leukocytes [48] \\
\hline & $\begin{array}{l}\text { Upregulation of tubular expression of CTGF, TGF } \beta \text {, } \\
\text { VEGF. Stimulated expression of IL- } 6 \text { and CCL- } 2 \text {. } \\
\text { Activation of NF- } \mathrm{kB}\end{array}$ & $\begin{array}{l}\text { Neoangiogenetic, profibrotic and proinflammatory PTEC } \\
\text { shift [51] }\end{array}$ \\
\hline
\end{tabular}

Proximal tubule (PT) Transforming growth factor beta (TGF $\beta$ ), Angiotensin II receptor type 1 (AT1), Vascular endothelial growth factor (VEGF), chemokine (C-C motif) ligand 2 (CCL-2), Mitogen-activated protein kinase (MAPK), Protein kinase C (PKC), Toll like receptor (TLR), Macrophage Inflammatory Protein-3 MIP-3 $\alpha$, Krueppel-like factor 6 (KLF6), serum and glucocorticoid-regulated kinase 1 (SGK-1), Hypoxia-inducible factors (HIF), Intercellular Adhesion Molecule 1(ICAM- 1), Signal transducer and activator of transcription 1 (STAT- 1), connective tissue growth factor (CTGF)

are widely available. It also reflects glomerular injury, as well as tubular dysfunction. However, its evolution is not predictable: microalbuminuria can regress towards normal values, progress towards macroalbuminuria, or remain stable for many years [64]. Moreover, there is evidence that DKD can develop with normoalbuminuria, and even though microalbuminuria is currently first-line screening for kidney involvement in DM, structural changes may appear in the glomerulus before it develops [65].

To overcome the limitations of microalbuminuria, new biomarkers in DKD are being sought. A clinically useful biomarker needs to be detectable early in the pathophysiological process of a disease, to have high sensitivity and specificity, and to provide high diagnostic and prognostic values. There are several novel and promising urinary biomarkers for renal damage in the early stages of DKD [64-66]. Urinary biomarkers in DKD can indicate the site of damage in the nephron, impaired function of the nephron, or the underlying pathophysiological process. We summarize these urinary biomarkers in DKD in Fig. 2, which outlines the principal tubular biomarkers that could be helpful in early detection of DKD.

What measurements are appropriate for detecting PT dysfunction in DKD? There are both functional and structural markers. One approach is to evaluate PT dysfunction by assessing impaired reabsorption of filtered proteins. The major site for filtered protein reabsorption is in the PT and assuming no significant post-glomerular degradation or secretion of these proteins, theoretically the more freely filtered the protein is, the greater should be the increment 


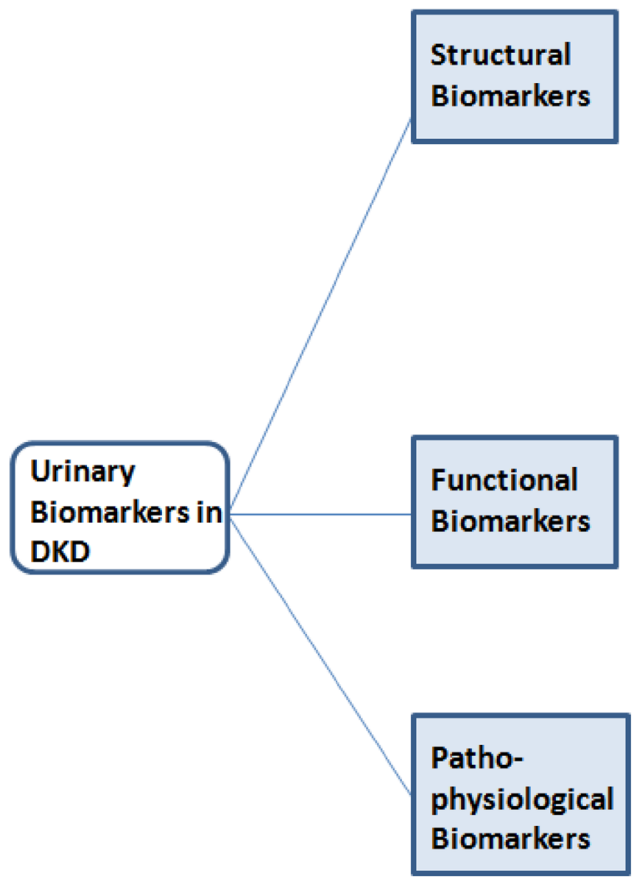

-Biomarkers reflecting Glomerular endothelial cells and Podocytes damage ( $\alpha$-actinin-4, Glycosaminoglycans, Lipocalin-Type Prostaglandin-D Synthase, Nephrin, Podocalyxin, Podocin, Synaptopodin, Vascular endothelial growth factor A, Wilms'Tumor-1)

-Biomarkers of Glomerular and Tubular basement membrane and extracellular matrix proteins alterations (Fibronectin, Laminin, Matrix metalloproteinase-9, Trasforming Growth factor- $\beta$-induced protein h3, Type I collagen fragments, Type IV collagen)

-Biomarkers of Tubular epithelial cells damage * (Alkaline phosphatase and $\psi$ Glutamyltransferase, Cubilin and Megalin, Glycoprotein non-metastatic melanoma protein B, Kidney injury molecule-1, Liver-Type Fatty Acid Binding Protein, Neutrophil gelatinase-associated lipocalin, $\mathrm{N}$-acetyl- $\beta$-D glucosaminidase)

-Functional glomerular barrier damage (Albumin, Angiotensinogen, Ceruloplasmin, Immunoglobulin G, Transferrin)

-Functional tubular reabsorptive damage * $\left(\alpha_{1}\right.$-microglobulin, $\beta_{2}$-microglobulin, Albumin, Cystatin C, Retinol Binding Protein 4)

- Oxidative Stress (Advanced Glycation End Products, Heart Fatty Acid Binding Protein, Pentosidine, 8-Hydroxy-2'-deoxyguanosine, 8-oxo-7,8-dihydro-2'deoxyguanosine)

-Inflammation (Interleukin 6, Monocyte Chemoattractant protein-1, Nitric Oxide, Orosomucoid, Tumor necrosis factor- $\alpha$ )

-Intra-renal renin-angiotensin system (Urine/plasma renin ratio)

-Growth Factors (Connective tissue growth factor, Trasforming growth factor $\beta 1$ )

Fig. 2 Classification of urinary biomarkers in diabetic kidney disease [64-66]. *Tubular biomarker further discussed in the text

in urinary excretion when the tubular reuptake process is disrupted. In this category of 'Functional Tubular Biomarkers' (FTB) are included plasma proteins of low molecular weight (LMWP) that are freely filtered by the glomerulus and almost fully reabsorbed by the PT. Another approach is to identify those substances excreted in urine as a result of tubular damage or regeneration. These 'Structural Tubular Biomarkers' (STB) are urinary enzymes that originate not from plasma, but directly from tubular cells.

In 'tubular' proteinuria, PT endocytic function is impaired and large amounts of LMWP appear in the urine, for example, UfRBP4 is elevated some 1,000-fold when endocytic function is completely abolished, as occurs in a number of monogenic tubular diseases [18]. The conventional explanation for increased excretion of LMWP is tubular disease. However, there is another possible mechanism of increased LMWP excretion in DM. There is evidence from at least one animal model that proteins compete for reabsorption by the proximal tubule [67]. There is also clinical evidence that the same pathway is used for uptake of filtered albumin and LMWP in humans, suggesting that two or more proteins might compete for reabsorption [68]. This would have the effect of increasing the excretion of a freely filtered plasma protein as a result of increased filtration of other proteins, such as albumin. This might occur when the size and charge permselectivity of the glomerulus is impaired in DKD. However, even early glomerular disease and loss of size and charge permselectivity in DM with increased albumin leakage may not cause microalbuminuria, if normal tubular function can reabsorb the excess albumin from the glomerular filtrate. The reserve capacity for protein uptake by the proximal tubule is unknown, but it is likely that the tubule has some reserve capacity for reabsorption; however, competition for reuptake between albumin and LMWP, as discussed earlier, may occur. Consequently, small increases in albumin leakage across the glomerulus in early DM may not cause 'microalbuminuria', but would be detected indirectly by measurement of increased LMWP excretion. Others have also proposed dissociation between increased glomerular leakage of albumin and microalbuminuria [22]. A possible limitation of the use of functional tubule biomarkers is an altered level in the serum (plasma overload) and/or alteration of glomerular filtration rate. 
The principal tubular biomarkers in DKD are briefly described in Table 3. The major strengths of several of them are [64-66]:

- a good correlation between the degree of damage at tubulo-interstitial level and the deterioration of renal function

- an early detection of tubule damage in the course of DKD

- tubular involvement in both T1DM and T2DM

- presence in normoalbuminuric patients

- a correlation with duration, severity and control of DM

- a progressive increase in patients with micro and macroalbuminuria.

The main limitation of tubular biomarkers is their poor independent predictive value for GFR decline and development of albuminuria, although there are conflicting findings in relation to their predictive value. One study assessed two tubular damage biomarkers, $\mathrm{N}$-acetyl- $\beta$-D glucosaminidase (NAG) and $\beta_{2}$ microglobulin. They did not add any prognostic benefit in detecting progressive renal impairment defined as a decline in eGFR of $\geq 50 \%$ from baseline, or start of dialysis, in T2DM, whereas histological findings of tubular atrophy and interstitial fibrosis (IFTA) did; although both NAG and $\beta_{2}$ microglobulin significantly correlated with the severity of tubulo-interstitial lesions. In fact, the IFTA scores were good predictors of renal prognosis, independent of other indicators of progression [70]. However, this was a retrospective analysis of over 25 years and over such a long period it is likely that both the sensitivity and accuracy of biomarker measurements have changed, as well as clinical care. A 3-year prospective intervention trial by Nielsen et al. found that T1DM patients with high levels of urinary NGAL and KIM-1 had a faster decline in GFR, suggesting that tubular damage is important for progression, even though the markers did not add to other markers of likely progression [71]. A limitation of this study was the storage of samples at only $-20{ }^{\circ} \mathrm{C}$ for 10 years before analysis. Tubular biomarkers are sensitive to their handling and storage conditions, and even $-70{ }^{\circ} \mathrm{C}$ can degrade over several years [72]. In a study by Conway et al. uKIM-1/Cr and $\mathrm{uGpnmb} / \mathrm{Cr}$ ratios were elevated in patients with incipient DN due to T2DM, suggesting an ongoing tubular injury. Both tubular biomarkers were correlated with the severity of proteinuria and with a faster decline in renal function. Nonetheless, neither uKIM-1/Cr nor uGpnmb/Cr ratio added significant prognostic value to ACR alone in a 4-year-follow up. Perhaps in can take many years before low-grade tubular injury translates to a decline in eGFR [73].

Nevertheless, there are other studies reporting that some tubular biomarkers do have a role in predicting the evolution of DKD. In 2010, Kern et al. showed that the baseline excretion of NAG and its increase over time independently predicted both micro- and macroalbuminuria in T1DM patients [74]. In $2011 \mathrm{Fu}$ et al. in a study of T2DM patients and healthy controls showed that NGAL increased significantly across the four groups from controls to normoalbuminuric, microalbuminuric and macroalbuminuric patients. In addition, NGAL as well as NAG, correlated with the urinary albumin-creatinine ratio (UACR) in the normoalbuminuric group, potentially predicting microalbuminuria and demonstrating a negative correlation with eGFR in the macroalbuminuria group. Furthermore, recent studies have explored the predictive value of tubular biomarkers in DKD [75]. In 2012, Soggiu et al. demonstrated increased retinol -binding protein 4 (RBP4) and $\alpha_{1}$-microglobulin in microalbuminuric patients. These results also showed a positive correlation between increases of LMWP and albuminuria. Thus, increased excretion of RBP4 and $\alpha_{1}$-microglobulin could be predictive of early-stage nephropathy in T1DM [76]. Recently, Panduru et al. showed that in a large cohort of patients with T1DM with a median follow up of 5.8 years, Liver-Type Fatty Acid Binding Protein (L-FABP) was an independent predictor of DKD evolution as assessed by progression from normo- to microalbuminuria, from microalbuminuria to macroalbuminuria, and from macroalbuminuria to ESRD [77]. A Korean group has also published results of 237 T2DM patients enrolled from May 2008 to December 2009, followed annually until March 2012 and screened for Cystatin $\mathrm{C}$ and non-albumin protein (NAP). Both measurements were significantly associated with a decline in eGFR after adjusting for age and several clinical confounders [78].

To clarify their utility in the clinical context of DM patients, longitudinal and prospective studies of biomarkers are needed, starting at an early phase of the disease. Given the instability of most proteins in urine, careful measures to reduce pre-analytical variations are critical for reliable results.

Finally, there is growing evidence for the potential of both proteomics and microRNA (miRNA) profiling to find new biomarkers for DKD. Although, it is not the aim of the present review, these two novel-approaches to discover new biomarkers are briefly considered in the context of DKD biomarker discovery. Essentially, both proteomic and miRNA approaches can explore DKD in a more dynamic and cross-sectional way that can consider structural, functional and pathophysiological pathways within the nephron as a continuum (Fig. 3).

Proteomic methods might provide a more dynamic phenotypic profile of the function and dysfunction of kidney cells, reflecting the complexity and pathophysiological changes at different stages of DKD. This methods may provide new insights into the pathogenesis of progression of DKD and might become early diagnostic biomarkers, specifically providing some functional or causative insights or associative patterns of markers (e.g. CKD273 
Table 3 Principal structural and functional tubular biomarkers overexpressed in the urine and explored in clinical background of diabetic kidney disease [18, 64-66, 69]. Proteins of Low Molecular Weight
(LMWP), Proximal tubule (PT), Proximal Tubule Epithelial Cells (PTECs), Molecular weight (MW), brush border (BB)

\section{Functional tubular biomarkers (FTB) \\ Retinol-binding protein 4}

Cystatin C

$\alpha_{1}$-microglobulin

$\beta_{2}$-microglobulin

Albumin

Structural tubular biomarkers (STB)

Neutrophil gelatinase-associated lipocalin (NGAL)

Kidney injury molecule-1 (KIM-1)

$\mathrm{N}$-acetyl- $\beta$-D glucosaminidase (NAG)

Liver-type fatty acid binding protein (L-FABP)

Cubilin and Megalin

Alkaline phosphatase (ALP) and $\gamma$-Glutamyltransferase (GGT)

Glycoprotein non-metastatic melanoma B (Gpnmb)
LMWP ( $21 \mathrm{kDa}$ when not bound to transthyretin), freely filtered by the glomerulus and almost completely reabsorbed in the PT. No tubular secretion. Measurement of free form of uRBP4 performs significantly better than previous measurement of total uRBP4 in the discrimination of patients with proximal renal tubular disorders

Cysteine protease inhibitor with MW $13 \mathrm{kDa}$ freely filtered by the glomerulus and almost entirely reabsorbed in the PT. No tubular secretion

Glycoprotein with MW 26-31 kDa. The unbound form is filtered freely through the renal glomerular basement membrane and is reabsorbed by the PTECs. No tubular secretion

LMWP (11.8 kDa) filtered by the glomerulus and is degradated in the PT via a megalin-dependent pathway. Unstable in urine

Molecular weight of $65 \mathrm{kDa}$; normally very little is filtered at the glomerulus. With glomerular barrier damage, filtration occurs and is followed by tubular reabsorption; the resulting albuminuria reflects the combined contribution of these two processes. Reserve capacity for reabsorption by PT is unknown

A $25 \mathrm{kDa}$ protein covalently bound to gelatinase from human neutrophils and part of the lipocalin family. NGAL is hyper-produced in the kidney tubules within a few hours after insults such as ischemia-reperfusion. It is freely filtered and reabsorbed in PT. Although it can be regarded as both FTB and STB, it is mainly considered a STB

A type 1 transmembrane protein expressed on the apical membrane of PT cells. Its ectodomain is cleaved and released into the lumen of the tubule and ultimately appears in the urine. KIM-1 facilitates repair of the damage by removing cellular debris and apoptotic bodies from the injured tubulointerstitial compartment. Elevated in acute kidney damage

Lysosomal brush border enzyme found in the PT cells. Because of its relatively high molecular weight $(>130 \mathrm{kDa})$, plasma NAG is not filtered though the glomeruli. NAG is released into the urine after renal tubule injury

Intracellular carrier protein expressed in the cytoplasm of human PT cells. MW: $14.2 \mathrm{kDa}$. Believed to have protective functions. Its excretion is associated with structural and functional tubular damage. Moreover, it is freely filtered and reabsorbed in PT. Although it can be regarded as both FTB and STB, it is mainly considered as a STB

Two apical membrane receptors responsible for endocytosis via clathrincoated vesicles, the central mechanism for protein reabsorption in the PT. Megalin is an approximately $600 \mathrm{kDa}$ transmembrane protein belonging to the LDL receptor family, and Cubilin is a slightly smaller peripheral membrane protein, approximately $460 \mathrm{kDa}$. Most proteins filtered through glomeruli have been identified as ligands of megalin, cubilin, or both

ALP is an enzyme with an MW 70-120 kDa. It is associated with the membranes of cell surfaces located in the PT, especially in the BB of epithelial cells. It originates from damaged renal tubules, and its levels are associated with the degree of damage. GGT is an enzyme with a molecular weight $\sim 90 \mathrm{kDa}$. It is present in the PT and the increased GGT excretion in the urine reflects the damage of the BB membrane and the loss of microvilli. The urinary levels of these enzymes/proteins are not influenced by their plasma levels

A transmembrane glycoprotein expressed on renal tubular cells. Increased during repair after renal ischemia—reperfusion injury. It may be a marker of tubular regeneration. Elevated in proteinuric renal diseases including diabetic nephropathy 
Fig. 3 Proteomics and MicroRNAs approach to DKD

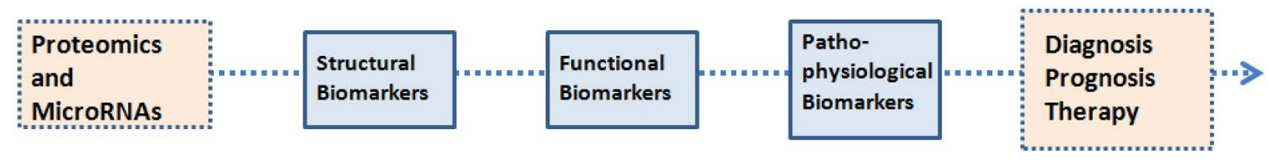

[79]) with reliable prognostic value in the clinical setting [80], but as yet it has not been able to replace albuminuria.

It has been shown that miRNAs, noncoding RNA singlestranded molecules, are found ubiquitously in body fluids (circulating miRNAs, urinary miRNAs, miRNAs have been found also in saliva, breast milk, cerebrospinal fluid) and that their dysregulation is closely linked to altered expression of regulatory proteins in many diseases. Interestingly, they have several intriguing features that make them suitable for being considered ideal biomarkers in many clinical settings. Abundantly expressed in cells, miRNAs can be tissue- and disease-specific markers. They are more resistant to degradation than proteins and mRNA. This feature has value in kidney diseases where urine has been one of the widely used sources of biomarkers, even though it can be an unstable milieu. The high stability under extreme handling and storage conditions of miRNAs may overcome this drawback and encourage the discovery of novel urinary biomarkers in kidney disease. MicroRNAs have been demonstrated to be a useful biomarker of kidney damage in both acute and chronic situations, such as acute kidney injury, various forms of chronic kidney disease, acute allograft rejection, and in chronic allograft dysfunction [81].

Current knowledge in the context of DKD seems to show that they can reflect fibrogenesis and expansion of the mesangial extracellular matrix [82]. In a study published in 2015, Argyropoulos et al. investigated the urine profile of T1DM patients still in a normoalbuminuric phase by comparing individuals who developed signs of nephropathy over an 18-year follow-up with those who did not. The results showed that miRNA profiles were different between the two groups long before some of them evolved from normo- to microalbuminuria [83], highlighting that changes in miRNA profiles are associated with different stages of DKD. The predicted target of differentially expressed miRNAs can map to specific pathways thought to be responsible for the development of progressive DKD, e.g., collagen production, inflammation, innate immunity, toll-like receptor signalling and neovascularization, supporting data for a role of miRNAs in regulating several functions and as potential therapeutic targets. In a later study using urinary exosomes, rather than cell-free circulating miRNAs, Delić et al. found that miRNA expression was altered among T2DM patients with nephropathy compared with T2DM patients without nephropathy, and healthy controls [84]. However, the pattern of miRNAs was different compared with that found in T1DM, and neither study revealed up-regulation of miR-192 expression, one of the most well studied miRNAs in DKD associated with increased renal fibrosis.

Given the gender-related differences in miRNAs found in T1DM patients [83], the different miRNAs expressed in T1 and T2DM, and the often inconsistent results using different sources of miRNAs (i.e. renal tissue, free urinary miRNAs or urinary exosomes), further studies are needed to fully understand and optimize their potential role in clinical practice.

\section{Conclusion}

We have explored the evidence for the contribution of the renal tubule to DKD. Diabetic tubulopathy is a real entity and although closely associated with glomerular damage, it may have a separate pathophysiology. Different metabolic and non-metabolic factors impair tubular function and probably determine some specific histological tubular changes in early and late stages of DKD. The limitations of microalbuminuria as an early and predictive biomarker of DKD still need to be overcome through the discovery and clinical evaluation of new functional or structural tubular biomarkers.

\section{Compliance with ethical standards}

Conflict of interest The authors declare that they have no conflict of interest.

Ethical approval This article does not contain any studies with human participants performed by any of the authors.

Open Access This article is distributed under the terms of the Creative Commons Attribution 4.0 International License (http://creativecommons.org/licenses/by/4.0/), which permits unrestricted use, distribution, and reproduction in any medium, provided you give appropriate credit to the original author(s) and the source, provide a link to the Creative Commons license, and indicate if changes were made.

\section{References}

1. Collins AJ, Foley RN, Chavers B, Gilbertson D, Herzog C, Johansen K, Kasiske B, Kutner N, Liu J, St Peter W, Guo H, Gustafson S, Heubner B, Lamb K, Li S, Li S, Peng Y, Qiu Y, Roberts T, Skeans M, Snyder J, Solid C, Thompson B, Wang C, Weinhandl E, Zaun D, Arko C, Chen SC, Daniels F, Ebben J, Frazier E, Hanzlik C, Johnson R, Sheets D, Wang X, Forrest B, Constantini E, Everson S, Eggers P, Agodoa L (2012) 'United States Renal Data System 2011 Annual Data Report: Atlas of 
chronic kidney disease \& end-stage renal disease in the United States. Am J Kidney Dis Off J Natl Kidney Found 59 (1 Suppl 1):A7, e1-420. doi:10.1053/j.ajkd.2011.11.015

2. International Diabetes federation (2015) IDF diabetes. 7 ed.. International Diabetes Federation, Brussels. http://www.diabetesatlas. org.

3. Haneda M, Utsunomiya K, Koya D, Babazono T, Moriya T, Makino H, Kimura K, Suzuki Y, Wada T, Ogawa S, Inaba M, Kanno Y, Shigematsu T, Masakane I, Tsuchiya K, Honda K, Ichikawa K, Shide K, Joint Committee on Diabetes N, Japanese Diabetes S, Japanese Society of N, Japanese Society for Dialysis T, Japan Society of M, Clinical N (2014) Classification of Diabetic Nephropathy 2014. Nihon Jinzo Gakkai shi 56 (5):547-552

4. Caramori ML, Fioretto P, Mauer M (2003) Low glomerular filtration rate in normoalbuminuric type 1 diabetic patients: an indicator of more advanced glomerular lesions. Diabetes 52(4):1036-1040

5. Perkins BA, Ficociello LH, Roshan B, Warram JH, Krolewski AS (2010) In patients with type 1 diabetes and new-onset microalbuminuria the development of advanced chronic kidney disease may not require progression to proteinuria. Kidney Int 77(1):57-64. doi:10.1038/ki.2009.399

6. Viazzi F, Piscitelli P, Giorda C, Ceriello A, Genovese S, Russo GT, Fioretto P, Guida P, De Cosmo S, Pontremoli R, Group AM-AS (2017) Association of kidney disease measures with risk of renal function worsening in patients with hypertension and type 2 diabetes. J Diabetes Complicat 31(2):419-426. doi:10.1016/j. jdiacomp.2016.10.030

7. Piscitelli P, Viazzi F, Fioretto P, Giorda C, Ceriello A, Genovese S, Russo G, Guida P, Pontremoli R, De De Cosmo S (2017) Predictors of chronic kidney disease in type 1 diabetes: a longitudinal study from the AMD Annals initiative. Sci Rep 7(1):3313. doi:10.1038/s41598-017-03551-w

8. Martinez-Castelao A, Navarro-Gonzalez JF, Gorriz JL, de Alvaro F (2015) The concept and the epidemiology of diabetic nephropathy have changed in recent years. J Clin Med 4(6):1207-1216. doi: $10.3390 /$ jcm 4061207

9. Ruggenenti P, Remuzzi G (2006) Time to abandon microalbuminuria? Kidney Int 70(7):1214-1222. doi:10.1038/sj.ki.5001729

10. Comper WD, Haraldsson B, Deen WM (2008) Resolved: normal glomeruli filter nephrotic levels of albumin. J Am Soc Nephrol JASN 19(3):427-432. doi:10.1681/ASN.2007090997

11. Tonneijck L, Muskiet MH, Smits MM, van Bommel EJ, Heerspink HJ, van Raalte DH, Joles JA (2017) Glomerular Hyperfiltration in Diabetes: Mechanisms, Clinical Significance, and Treatment. J Am Soc Nephrol JASN. doi:10.1681/ASN.2016060666

12. Gibb DM, Tomlinson PA, Dalton NR, Turner C, Shah V, Barratt TM (1989) Renal tubular proteinuria and microalbuminuria in diabetic patients. Arch Dis Child 64(1):129-134

13. Tojo A, Onozato ML, Ha H, Kurihara H, Sakai T, Goto A, Fujita T, Endou H (2001) Reduced albumin reabsorption in the proximal tubule of early-stage diabetic rats. Histochem Cell Biol 116(3):269-276. doi:10.1007/s004180100317

14. Russo LM, Sandoval RM, Campos SB, Molitoris BA, Comper WD, Brown D (2009) Impaired tubular uptake explains albuminuria in early diabetic nephropathy. J Am Soc Nephrol JASN 20(3):489-494. doi:10.1681/ASN.2008050503

15. Russo LM, Sandoval RM, McKee M, Osicka TM, Collins AB, Brown D, Molitoris BA, Comper WD (2007) The normal kidney filters nephrotic levels of albumin retrieved by proximal tubule cells: retrieval is disrupted in nephrotic states. Kidney Int 71(6):504-513. doi:10.1038/sj.ki.5002041

16. Osicka TM, Strong KJ, Nikolic-Paterson DJ, Atkins RC, Jerums G, Comper WD (2004) Renal processing of serum proteins in an albumin-deficient environment: an in vivo study of glomerulonephritis in the Nagase analbuminaemic rat. Nephrol Dial Transplant Off Publ Eur Dial Transpl Assoc Eur Renal Assoc 19 (2):320-328

17. Norden AG, Lapsley M, Lee PJ, Pusey CD, Scheinman SJ, Tam FW, Thakker RV, Unwin RJ, Wrong O (2001) Glomerular protein sieving and implications for renal failure in Fanconi syndrome. Kidney Int 60(5):1885-1892. doi:10.1046/j.1523-1755.2001.00016.x

18. Burling KA, Cutillas PR, Church D, Lapsley M, Norden AG (2012) Analysis of molecular forms of urine Retinol-Binding Protein in Fanconi Syndrome and design of an accurate immunoassay. Clinica chimica acta; Int J Clin Chem 413 (3-4):483-489. doi:10.1016/j.cca.2011.11.007

19. Dickson LE, Wagner MC, Sandoval RM, Molitoris BA (2014) The proximal tubule and albuminuria: really! J Am Soc Nephrol JASN 25(3):443-453. doi:10.1681/ASN.2013090950

20. Wagner MC, Campos-Bilderback SB, Chowdhury M, Flores B, Lai X, Myslinski J, Pandit S, Sandoval RM, Wean SE, Wei Y, Satlin LM, Wiggins RC, Witzmann FA, Molitoris BA (2016) Proximal tubules have the capacity to regulate uptake of albumin. J Am Soc Nephrol JASN 27(2):482-494. doi:10.1681/ASN.2014111107

21. Ng DP, Tai BC, Tan E, Leong H, Nurbaya S, Lim XL, Chia KS, Wong CS, Lim WY, Holthofer H (2011) Nephrinuria associates with multiple renal traits in type 2 diabetes. Nephrol Dial Transplant Off Publ Eur Dial Transpl Assoc Eur Renal Assoc 26 (8):2508-2514. doi:10.1093/ndt/gfq738

22. Petrica L, Vlad A, Gluhovschi G, Gadalean F, Dumitrascu V, Gluhovschi C, Velciov S, Bob F, Vlad D, Popescu R, Milas O, Ursoniu S (2014) Proximal tubule dysfunction is associated with podocyte damage biomarkers nephrin and vascular endothelial growth factor in type 2 diabetes mellitus patients: a crosssectional study. PloS One 9(11):e112538. doi:10.1371/journal. pone. 0112538

23. Thrailkill KM, Nimmo T, Bunn RC, Cockrell GE, Moreau CS, Mackintosh S, Edmondson RD, Fowlkes JL (2009) Microalbuminuria in type 1 diabetes is associated with enhanced excretion of the endocytic multiligand receptors megalin and cubilin. Diabetes Care 32(7):1266-1268. doi:10.2337/dc09-0112

24. Tojo A, Kinugasa S (2012) Mechanisms of glomerular albumin filtration and tubular reabsorption. Int. J Nephrol 2012:481520. doi: $10.1155 / 2012 / 481520$

25. Liu WJ, Shen TT, Chen RH, Wu HL, Wang YJ, Deng JK, Chen QH, Pan Q, Huang Fu CM, Tao JL, Liang D, Liu HF (2015) Autophagy-lysosome pathway in renal tubular epithelial cells is disrupted by advanced glycation end products in diabetic nephropathy. J Biol Chem 290(33):20499-20510. doi:10.1074/ jbc.M115.666354

26. Long YS, Zheng S, Kralik PM, Benz FW, Epstein PN (2016) Impaired albumin uptake and processing Promote albuminuria in OVE26 diabetic mice. J Diabetes Res 2016:8749417. doi:10.1155/2016/8749417

27. Mori KP, Yokoi H, Kasahara M, Imamaki H, Ishii A, Kuwabara T, Koga K, Kato Y, Toda N, Ohno S, Kuwahara K, Endo T, Nakao K, Yanagita M, Mukoyama M, Mori K (2017) Increase of total nephron albumin filtration and reabsorption in diabetic nephropathy. J Am Soc Nephrol JASN 28(1):278-289. doi:10.1681/ ASN.2015101168

28. Remuzzi G, Ruggenenti P, Benigni A (1997) Understanding the nature of renal disease progression. Kidney Int 51(1):2-15

29. Nielsen R, et al (2013) Increased lysosomal proteolysis counteracts protein accumulation in the proximal tubule during focal segmental glomerulosclerosis. Kidney international 84(5):902-910

30. Guo JK, Marlier A, Shi H, Shan A, Ardito TA, Du ZP, Kashgarian M, Krause DS, Biemesderfer D, Cantley LG (2012) Increased tubular proliferation as an adaptive response to 
glomerular albuminuria. J Am Soc Nephrol JASN 23(3):429437. doi:10.1681/ASN.2011040396

31. Anders HJ, Davis JM, Thurau K (2016) Nephron protection in diabetic kidney disease. N Engl J Med 375(21):2096-2098. doi:10.1056/NEJMcibr1608564

32. Fu WJ, Li BL, Wang SB, Chen ML, Deng RT, Ye CQ, Liu L, Fang AJ, Xiong SL, Wen S, Tang HH, Chen ZX, Huang ZH, Peng LF, Zheng L, Wang Q (2012) Changes of the tubular markers in type 2 diabetes mellitus with glomerular hyperfiltration. Diabetes Res Clin Pract 95(1):105-109. doi:10.1016/j. diabres.2011.09.031

33. Vallon V, Gerasimova M, Rose MA, Masuda T, Satriano J, Mayoux E, Koepsell H, Thomson SC, Rieg T (2014) SGLT2 inhibitor empagliflozin reduces renal growth and albuminuria in proportion to hyperglycemia and prevents glomerular hyperfiltration in diabetic Akita mice. Am J Physiol Renal Physiol 306 (2):F194-204. doi:10.1152/ajprenal.00520.2013

34. Vallon V (2015) The mechanisms and therapeutic potential of SGLT2 inhibitors in diabetes mellitus. Annu Rev Med 66:255270. doi:10.1146/annurev-med-051013-110046

35. Wanner C, Inzucchi SE, Zinman B (2016) Empagliflozin and progression of kidney disease in type 2 diabetes. N Engl J Med 375(18):1801-1802. doi:10.1056/NEJMc1611290

36. Novikov A, Vallon V (2016) Sodium glucose cotransporter 2 inhibition in the diabetic kidney: an update. Curr Opin Nephrol Hypertens 25(1):50-58. doi:10.1097/MNH.0000000000000187

37. van Bommel EJ, Muskiet MH, Tonneijck L, Kramer MH, Nieuwdorp M, van Raalte DH (2017) SGLT2 Inhibition in the Diabetic Kidney-From Mechanisms to Clinical Outcome. Clin J Am Soc Nephrol. doi:10.2215/CJN.06080616

38. Song P, Onishi A, Koepsell H, Vallon V (2016) Sodium glucose cotransporter SGLT1 as a therapeutic target in diabetes mellitus. Expert Opin Ther Targets 20(9):1109-1125. doi:10.1517/14728 222.2016.1168808

39. Rieg T, Masuda T, Gerasimova M, Mayoux E, Platt K, Powell DR, Thomson SC, Koepsell H, Vallon V (2014) Increase in SGLT1mediated transport explains renal glucose reabsorption during genetic and pharmacological SGLT2 inhibition in euglycemia. Am J Physiol Renal Physiol 306 (2):F188-193. doi:10.1152/ ajprenal.00518.2013

40. Abdul-Ghani MA, DeFronzo RA, Norton L (2013) Novel hypothesis to explain why SGLT2 inhibitors inhibit only $30-50 \%$ of filtered glucose load in humans. Diabetes 62(10):3324-3328. doi:10.2337/db13-0604

41. Powell DR, DaCosta CM, Gay J, Ding ZM, Smith M, Greer J, Doree D, Jeter-Jones S, Mseeh F, Rodriguez LA, Harris A, Buhring L, Platt KA, Vogel P, Brommage R, Shadoan MK, Sands AT, Zambrowicz B (2013) Improved glycemic control in mice lacking Sglt1 and Sglt2. Am J Physiol Endocrinol Metab 304(2):E117-E130. doi:10.1152/ajpendo.00439.2012

42. Vallon V, Thomson SC (2017) Targeting renal glucose reabsorption to treat hyperglycaemia: the pleiotropic effects of SGLT2 inhibition. Diabetologia 60(2):215-225. doi:10.1007/ s00125-016-4157-3

43. Marks J, Carvou NJ, Debnam ES, Srai SK, Unwin RJ (2003) Diabetes increases facilitative glucose uptake and GLUT2 expression at the rat proximal tubule brush border membrane. J Physiol 553 (Pt 1):137-145. doi:10.1113/jphysiol.2003.046268

44. Wright EM, Loo DD, Hirayama BA (2011) Biology of human sodium glucose transporters. Physiol Rev 91(2):733-794. doi:10.1152/physrev.00055.2009

45. Wakisaka M (2016) Empagliflozin and progression of kidney disease in type 2 diabetes. N Engl J Med 375(18):1799-1800. doi:10.1056/NEJMc1611290

46. Wakisaka M, Nagao T, Yoshinari M (2016) Sodium glucose cotransporter 2 (SGLT2) plays as a physiological glucose sensor and regulates cellular contractility in rat mesangial cells. PloS One 11(3):e0151585. doi:10.1371/journal.pone.0151585

47. Ferrannini E, Mark M, Mayoux E (2016) CV protection in the EMPA-reg outcome Trial: a "thrifty substrate" hypothesis. Diabetes Care 39(7):1108-1114. doi:10.2337/dc16-0330

48. Tang SC, Leung JC, Lai KN (2011) Diabetic tubulopathy: an emerging entity. Contrib Nephrol 170:124-134. doi:10.1159/000325647

49. Gilbert RE, Cooper ME (1999) The tubulointerstitium in progressive diabetic kidney disease: more than an aftermath of glomerular injury? Kidney Int 56(5):1627-1637. doi:10.1046/j.1523-1755.1999.00721.x

50. Vallon V, Komers R (2011) Pathophysiology of the diabetic kidney. Compr Physiol 1(3):1175-1232. doi:10.1002/cphy.c100049

51. Tang SC, Lai KN (2012) The pathogenic role of the renal proximal tubular cell in diabetic nephropathy. Nephrol Dial Transplant Off Publ Eur Dial Transpl Assoc Eur Renal Assoc 27 (8):3049-3056. doi:10.1093/ndt/gfs260

52. Bonventre JV (2012) Can we target tubular damage to prevent renal function decline in diabetes? Semin Nephrol 32(5):452-462. doi:10.1016/j.semnephrol.2012.07.008

53. Tessari $\mathrm{P}$ (2015) Nitric oxide in the normal kidney and in patients with diabetic nephropathy. J Nephrol 28(3):257-268. doi:10.1007/ s40620-014-0136-2

54. Menzies RI, Tam FW, Unwin RJ, Bailey MA (2016) Purinergic signaling in kidney disease. Kidney Int. doi:10.1016/j. kint.2016.08.029

55. Chen K, Zhang J, Zhang W, Zhang J, Yang J, Li K, He Y (2013) ATP-P2 $\times 4$ signaling mediates NLRP3 inflammasome activation: a novel pathway of diabetic nephropathy. Int J Biochem Cell Biol 45(5):932-943. doi:10.1016/j.biocel.2013.02.009

56. Jenkin KA, Verty AN, McAinch AJ, Hryciw DH (2012) Endocannabinoids and the renal proximal tubule: an emerging role in diabetic nephropathy. Int J Biochem Cell Biol 44(11):2028-2031. doi:10.1016/j.biocel.2012.07.008

57. Slyne J, Slattery C, McMorrow T, Ryan MP (2015) New developments concerning the proximal tubule in diabetic nephropathy: in vitro models and mechanisms. Nephrol Dial Transplant Off Publ Eur Dial Transpl Assoc Eur Renal Assoc 30 Suppl 4:iv60 67. doi:10.1093/ndt/gfv264

58. Pourghasem M, Shafi H, Babazadeh Z (2015) Histological changes of kidney in diabetic nephropathy. Caspian. J Intern Med 6(3):120-127

59. Brito PL, Fioretto P, Drummond K, Kim Y, Steffes MW, Basgen JM, Sisson-Ross S, Mauer M (1998) Proximal tubular basement membrane width in insulin-dependent diabetes mellitus. Kidney Int 53(3):754-761. doi:10.1046/j.1523-1755.1998.00809.x

60. Fioretto P, Mauer M (2007) Histopathology of diabetic nephropathy. Semin Nephrol 27(2):195-207. doi:10.1016/j. semnephrol.2007.01.012

61. Vallon V, Thomson SC (2012) Renal function in diabetic disease models: the tubular system in the pathophysiology of the diabetic kidney. Annu Rev Physiol 74:351-375. doi:10.1146/ annurev-physiol-020911-153333

62. Najafian B, Kim Y, Crosson JT, Mauer M (2003) Atubular glomeruli and glomerulotubular junction abnormalities in diabetic nephropathy. J Am Soc Nephrol JASN 14(4):908-917

63. Viazzi F, Cappadona F, Pontremoli R (2016) Microalbuminuria in primary hypertension: a guide to optimal patient management? J Nephrol 29(6):747-753. doi:10.1007/s40620-016-0335-0

64. Gluhovschi C, Gluhovschi G, Petrica L, Timar R, Velciov S, Ionita I, Kaycsa A, Timar B (2016) Urinary Biomarkers in the Assessment of Early Diabetic Nephropathy. J Diabetes Res 2016:4626125. doi:10.1155/2016/4626125

65. Moresco RN, Sangoi MB, De Carvalho JA, Tatsch E, Bochi GV (2013) Diabetic nephropathy: traditional to proteomic markers. 
Clinica chimica acta; Int J Clin Chem 421:17-30. doi:10.1016/j. cca.2013.02.019

66. Lee SY, Choi ME (2015) Urinary biomarkers for early diabetic nephropathy: beyond albuminuria. Pediatric nephrology 30(7):1063-1075. doi:10.1007/s00467-014-2888-2

67. Bernard A, Amor AO, Viau C, Lauwerys R (1988) The renal uptake of proteins: a nonselective process in conscious rats. Kidney Int 34(2):175-185

68. Norden AG, Scheinman SJ, Deschodt-Lanckman MM, Lapsley M, Nortier JL, Thakker RV, Unwin RJ, Wrong O (2000) Tubular proteinuria defined by a study of Dent's (CLCN5 mutation) and other tubular diseases. Kidney Int 57(1):240-249. doi:10.1046/j.1523-1755.2000.00847.x

69. Tramonti G, Kanwar YS (2013) Review and discussion of tubular biomarkers in the diagnosis and management of diabetic nephropathy. Endocr 43(3):494-503. doi:10.1007/s12020-012-9820-y

70. Mise K, Hoshino J, Ueno T, Hazue R, Hasegawa J, Sekine A, Sumida K, Hiramatsu R, Hasegawa E, Yamanouchi M, Hayami N, Suwabe T, Sawa N, Fujii T, Hara S, Ohashi K, Takaichi K, Ubara Y (2016) Prognostic value of tubulo-interstitial lesions, urinary $\mathrm{N}$-acetyl-beta-d-glucosaminidase, and urinary beta2-microglobulin in patients with type 2 diabetes and biopsy-proven diabetic nephropathy. Clin J Am Soc Nephrol 11(4):593-601. doi:10.2215/ CJN.04980515

71. Nielsen SE, Andersen S, Zdunek D, Hess G, Parving HH, Rossing $P$ (2011) Tubular markers do not predict the decline in glomerular filtration rate in type 1 diabetic patients with overt nephropathy. Kidney Int 79(10):1113-1118. doi:10.1038/ki.2010.554

72. Mao J, Chen S, Na Z, Xhang Y, Huang Y, Li Y (1996) Frozen storage of urine samples before ELISA measurement of retinolbinding protein. Clin Chem 42(3):466-467

73. Conway BR, Manoharan D, Manoharan D, Jenks S, Dear JW, McLachlan S, Strachan MW, Price JF (2012) Measuring urinary tubular biomarkers in type 2 diabetes does not add prognostic value beyond established risk factors. Kidney Int 82(7):812-818. doi:10.1038/ki.2012.218

74. Kern EF, Erhard P, Sun W, Genuth S, Weiss MF (2010) Early urinary markers of diabetic kidney disease: a nested case-control study from the diabetes control and complications trial (DCCT). Am J Kidney Dis Off J Natl Kidney Found 55(5):824-834. doi:10.1053/j.ajkd.2009.11.009
75. Fu WJ, Xiong SL, Fang YG, Wen S, Chen ML, Deng RT, Zheng L, Wang SB, Pen LF, Wang Q (2012) Urinary tubular biomarkers in short-term type 2 diabetes mellitus patients: a cross-sectional study. Endocr 41(1):82-88. doi:10.1007/s12020-011-9509-7

76. Soggiu A, Piras C, Bonizzi L, Hussein HA, Pisanu S, Roncada $\mathrm{P}$ (2012) A discovery-phase urine proteomics investigation in type 1 diabetes. Acta Diabetol 49(6):453-464. doi:10.1007/ s00592-012-0407-0

77. Panduru NM, Forsblom C, Saraheimo M, Thorn L, Bierhaus A, Humpert PM, Groop PH, FinnDiane Study G (2013) Urinary liver-type fatty acid-binding protein and progression of diabetic nephropathy in type 1 diabetes. Diabetes Care 36(7):2077-2083. doi: $10.2337 / \mathrm{dc} 12-1868$

78. Kim SS, Song SH, Kim IJ, Jeon YK, Kim BH, Kwak IS, Lee EK, Kim YK (2013) Urinary cystatin C and tubular proteinuria predict progression of diabetic nephropathy. Diabetes Care 36(3):656-661. doi:10.2337/dc12-0849

79. Zurbig P, Jerums G, Hovind P, Macisaac RJ, Mischak H, Nielsen SE, Panagiotopoulos S, Persson F, Rossing P (2012) Urinary proteomics for early diagnosis in diabetic nephropathy. Diabetes 61(12):3304-3313. doi:10.2337/db12-0348

80. Papale M, Di Paolo S, Vocino G, Rocchetti MT, Gesualdo L (2014) Proteomics and diabetic nephropathy: what have we learned from a decade of clinical proteomics studies? J Nephrol 27(3):221-228. doi:10.1007/s40620-014-0044-5

81. Saikumar J, Ramachandran K, Vaidya VS (2014) Noninvasive micromarkers. Clin Chem 60(9):1158-1173. doi:10.1373/ clinchem.2013.216044

82. Simpson K, Wonnacott A, Fraser DJ, Bowen T (2016) MicroRNAs in diabetic nephropathy: from biomarkers to therapy. Curr Diab Rep 16(3):35. doi:10.1007/s11892-016-0724-8

83. Argyropoulos C, Wang K, Bernardo J, Ellis D, Orchard T, Galas D, Johnson JP (2015) Urinary MicroRNA profiling predicts the development of microalbuminuria in patients with type 1 diabetes. J Clin Med 4(7):1498-1517. doi:10.3390/jcm4071498

84. Delić D, Eisele C, Schmid R, Baum P, Wiech F, Gerl M, Zimdahl H, Pullen SS, Urquhart R (2016) Urinary exosomal miRNA signature in type II diabetic nephropathy patients. PloS One 11(3):e0150154. doi:10.1371/journal.pone.0150154 